\title{
Association of Hyperparathyroidism and Papillary Thyroid Cancer: A Multicenter Retrospective Study
}

\author{
Chaiho Jeong ${ }^{1}$, Hye In Kwon ${ }^{2}$, Hansang Baek ${ }^{1}$, Hun-Sung Kim ${ }^{1,3}$, Dong-Jun Lim ${ }^{1}$, Ki-Hyun Baek ${ }^{2}$, Jeonghoon Ha ${ }^{1}$, \\ Moo Il Kang ${ }^{1}$ \\ ${ }^{1}$ Division of Endocrinology and Metabolism, Department of Internal Medicine, Seoul St. Mary's Hospital, College of Medicine, \\ The Catholic University of Korea; ${ }^{2}$ Division of Endocrinology and Metabolism, Department of Internal Medicine, Yeouido St. \\ Mary's Hospital, College of Medicine, The Catholic University of Korea; ${ }^{3}$ Department of Medical Informatics, Seoul St. Mary's \\ Hospital, College of Medicine, The Catholic University of Korea, Seoul, Korea
}

Background: Concomitant papillary thyroid cancer (PTC) and hyperparathyroidism (HPT) have been reported in several studies. Our study aimed to investigate the incidence of concomitant PTC in HPT patients upon preoperative diagnosis and present a clinical opinion on detecting thyroid malignancy in case of parathyroidectomy.

Methods: Patients who underwent parathyroidectomy between January 2009 and December 2019 in two medical centers were included. Of the 279 participants 154 were diagnosed as primary hyperparathyroidism (pHPT) and 125 as secondary hyperparathyroidism (sHPT). The incidence of concomitant PTC and its clinical characteristics were compared with 98 patients who underwent thyroidectomy and were diagnosed with classical PTC during the same period.

Results: Concurrent PTC was detected in 14 patients (9.1\%) with pHPT and in nine patients (7.2\%) with sHPT. Ten (71.4\%) and seven (77.8\%) PTCs were microcarcinomas in the pHPT and sHPT cases respectively. In the pHPT patients, vitamin D was lower in the $\mathrm{pHPT}+\mathrm{PTC}$ group $(13.0 \pm 3.7 \mathrm{ng} / \mathrm{mL})$ than in the $\mathrm{pHPT}$-only group $(18.5 \pm 10.4 \mathrm{ng} / \mathrm{mL} ; P=0.01)$. Vitamin $\mathrm{D}$ levels were also lower in the sHPT+PTC group $(12.3 \pm 5.6 \mathrm{ng} / \mathrm{mL})$ than in the sHPT-only group $(18.0 \pm 10.2 \mathrm{ng} / \mathrm{mL} ; P=0.12)$. In the concomitant PTC group, lymph node ratio was higher than in the classical PTC group $(P=0.00)$.

Conclusion: A high prevalence of concomitant PTC was seen in patients with pHPT and sHPT. Those concomitant PTCs were mostly microcarcinomas and had more aggressive features, suggesting that efforts should be made to detect concomitant malignancies in the preoperative parathyroidectomy evaluation.

Keywords: Hyperparathyroidism, primary; Hyperparathyroidism, secondary; Parathyroidectomy; Thyroid cancer, papillary

Received: 27 May 2020, Revised: 1 October 2020, Accepted: 5 November 2020 Corresponding authors: Jeonghoon $\mathrm{Ha}$

Division of Endocrinology and Metabolism, Department of Internal Medicine, Seoul St. Mary's Hospital, College of Medicine, The Catholic University of Korea, 222 Banpo-daero, Seocho-gu, Seoul 06591, Korea

Tel: +82-2-2258-6372, Fax: +82-2-599-3589, E-mail: hajhoon@catholic.ac.kr

\section{Copyright $(92020$ Korean Endocrine Society}

This is an Open Access article distributed under the terms of the Creative Commons Attribution Non-Commercial License (https://creativecommons.org/ licenses/by-nc/4.0/) which permits unrestricted non-commercial use, distribution, and reproduction in any medium, provided the original work is properly cited.

Moo Il Kang

Division of Endocrinology and Metabolism, Department of Internal Medicine, Seoul St. Mary's Hospital, College of Medicine, The Catholic University of Korea, 222 Banpo-daero, Seocho-gu, Seoul 06591, Korea

Tel: +82-2-2258-6372, Fax: +82-2-599-3589, E-mail: mikang@catholic.ac.kr 


\section{INTRODUCTION}

The prevalence of primary hyperparathyroidism (pHPT) is $0.1 \%$ to $0.4 \%$ in the general population [1] and its incidence is increasing, leading to an increased need for surgical management $[2,3]$. Usually, it is caused by a solitary parathyroid adenoma and surgical resection is the choice of treatment [4]. Secondary hyperparathyroidism (sHPT) results from compensatory parathyroid hyperfunction in response to chronic hypocalcemia caused by renal failure. Some patients with sHPT need parathyroidectomy in an attempt to reduce severe complications, such as renal osteodystrophy, caused by high levels of parathyroid hormone (PTH) [5]. The burden of sHPT is unknown, but despite the use of multiple medical therapies, the rate of parathyroidectomy in sHPT patients refractory to medical therapy has not declined in recent years [6].

Concomitant pHPT and thyroid malignancy have been reported in several studies since the first cases were reported by Ogburn and Black [7] in 1956. In pHPT patients, several studies reported the prevalence of papillary thyroid cancer (PTC) to range from $2 \%$ to $15 \%[8,9]$. Data on the association between sHPT and PTC is more limited. sHPT and coexisting PTC have been reported in sporadic cases and studies are scarce [10]. Today, the number of experts proposing routine bilateral neck exploration has decreased and the paradigm has recently shifted to minimally invasive parathyroidectomy [11], offering a more limited exposure of the thyroid gland, making the detection of concomitant thyroid malignancy difficult during surgery. The presence of concomitant PTC can change the evaluation and surgical management of patients with hyperparathyroidism (HPT). In the coexistence of these two diseases, thyroid PTC must be identified prior to surgical management to minimize complications from additional surgical procedures, patient discomfort, and costs [12].

Thus, our study aimed to further investigate the incidence in our centers and the clinical characteristics of concomitant PTC in HPT patients with a special emphasis on preoperative diagnosis. We also aimed to provide a clinical opinion on the need for detecting PTC when preparing for parathyroidectomy.

\section{METHODS}

\section{Data sources}

We retrospectively evaluated 279 patients (patients from Seoul St. Mary's Hospital and patients from Yeouido St. Mary's Hospital) who underwent parathyroidectomy between January 2009 and December 2019. Patient clinical data and pathological results were obtained from the hospital's electronic registry. Initially, 319 patients were screened, of whom 40 cases were excluded: due to multiple endocrine neoplasia syndrome (MEN) $(n=15)$; parathyroid carcinoma $(n=8)$; missing data or insufficient medical records $(n=12)$; or because they underwent parathyroidectomy for diseases other than HPT $(n=5)$. Of the 279 participants, 154 were diagnosed with pHPT and 125 with sHPT (Fig. 1). The clinical findings were compared between 98 age and sex-matched patients who underwent thyroidectomy

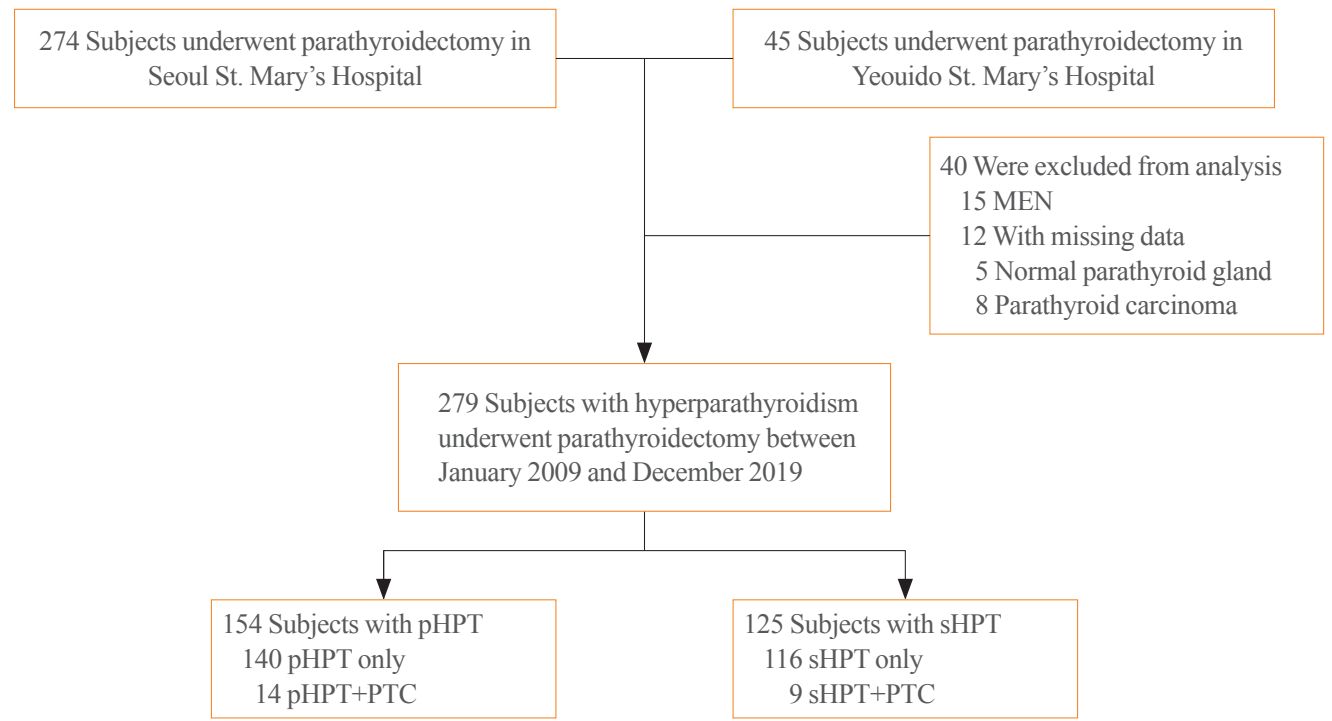

Fig. 1. Enrollment of the study subjects. MEN, multiple endocrine neoplasia; pHPT, primary hyperparathyroidism; PTC, papillary thyroid cancer; sHPT, secondary hyperparathyroidism. 
and were diagnosed with classical PTC in our clinic during the same period. The study adhered to the tenets of the Declaration of Helsinki and was approved by the Institutional Review Board of Catholic Medical Center (No. KC19TESI0523). Informed consent was exempted by the review board since the study was a retrospective analysis.

\section{Indications for parathyroidectomy}

The indications for parathyroidectomy were as follows. For the pHPT subjects, parathyroidectomy was recommended according to the following guidelines from the Fourth International Workshop [13]: (1) serum calcium $>1 \mathrm{mg} / \mathrm{dL}$ above the upper limit of normal; (2) peri- or postmenopausal women and men age 50 and older with a T-score of -2.5 or less; (3) the presence of vertebral fracture; (4) a creatinine clearance of $<60 \mathrm{~mL} / \mathrm{min}$; (5) the presence of renal stones or nephrocalcinosis in renal imaging; (6) the presence of marked hypercalciuria ( $>400 \mathrm{mg} /$ day); and (7) age under 50 years. Parathyroidectomy for sHPT was indicated for patients refractory to medical therapy: (1) persistent hypercalcemia or hyperphosphatemia; (2) an elevated risk or presence of calciphylaxis; and (3) erythropoietin-resistant anemia [14].

\section{Measurements}

All patients underwent preoperative ultrasonography (US) and their thyroid nodules were screened. PTC was diagnosed by fine needle aspiration (FNA) of the suspected thyroid nodule seen in preoperative US or confirmed by pathology after resection. The baseline laboratory findings were measured before surgery. The biochemical and hormonal findings, including serum immuno-reactive intact PTH levels (reference range, 8 to 76 pg/mL; Cobra 5010, A Packard Bioscience Company, Meriden, CT, USA), total serum calcium ( 8 to $10 \mathrm{mg} / \mathrm{dL}$ ), phosphorous (2.6 to $4.5 \mathrm{mg} / \mathrm{dL}$ ), albumin, blood urea nitrogen, creatinine (Hitachi 7600, Hitachi, Tokyo, Japan), serum 25-hydroxyvitamin D (25(OH)D, 0 to $20 \mathrm{ng} / \mathrm{mL}$; ADVIA Centaur XPT, Siemens Healthcare Diagnostics Inc., Tarrytown, NY, USA), and 24-hour urine calcium were evaluated. Serum calcium was corrected for changes in the serum albumin concentration according to the following formula: corrected calcium $(\mathrm{mg} /$ $\mathrm{dL})=$ actual calcium $+(4-$ serum albumin $) \times 0.8$. Body mass index was calculated as body weight in kilograms divided by height in meters squared. Bone mineral density was evaluated using dual-energy X-ray absorptiometry (Lunar Prodigy, GE Healthcare, Madison, WI, USA) before parathyroidectomy.

The PTC tumor size and pathology of the parathyroid specimens were described in the pathology analysis report. Tumor size was defined as the largest dimension. Microcarcinoma was defined as cancer where the greatest dimension was $\leq 1 \mathrm{~cm}$. The calcification pattern was classified into the following three groups according to the consensus statement and recommendations proposed by the Korean Society of Thyroid Radiology and the Korean Society of Radiology [15]: (1) no calcification; (2) microcalcification defined as the presence of punctate echogenic foci of $<1 \mathrm{~mm}$ with or without posterior shadowing; (3) macrocalcification defined as the presence of echogenic foci $>1$ mm with posterior shadowing [16]. The Korean Thyroid Imaging Reporting and Data System (K-TIRADS) was used to classify preoperative thyroid nodules for biopsy recommendation [17]. Lymph node metastases were considered positive if they were proven by pathology finding. Prophylactic central neck lymph node dissection was the standard surgical procedure for lymph node dissection in both institutions. The lymph node ratio (LNR) was defined as the number of metastatic lymph nodes divided by the number of lymph nodes removed. B-type Raf kinase (BRAF) mutations were analyzed by immunohistochemistry in the PTC specimens.

\section{Statistical analysis}

The continuous variables are expressed as mean \pm standard deviation or median (interquartile range) as appropriate. The categorical variables are presented as number and frequency (proportions, \%). Comparisons of the means and proportions were performed with independent sample $t$ tests or the Mann-Whitney test. The comparison of categorical variables was performed with Fisher's exact test or chi-square analysis. A two-tailed $P$ value of less than 0.05 was considered statistically significant. All statistical analyses were performed using IBM SPSS Statistics for Windows version 24.0 (IBM Corp., Armonk, NY, USA).

\section{RESULTS}

\section{Clinical and biochemical characteristics of pHPT patients}

The demographic, clinical, biochemical, and histopathological characteristics of the pHPT patients are described in Table 1. Concurrent PTC was detected in 14 patients (9.1\%) with pHPT. pHPT was more prevalent in females $(75.7 \%)$. There was no difference in sex and age between the subjects with pHPT and those with pHPT+PTC. The PTH level was $206.8 \pm 164.3 \mathrm{pg} / \mathrm{mL}$ in the pHPT-only group and $207.4 \pm 138.7 \mathrm{pg} / \mathrm{mL}$ in the $\mathrm{pHPT}+$ PTC group, with no significant difference between the two groups $(P=0.53)$. The serum calcium and 24-hour urine calcium levels were not different between the two groups. $25(\mathrm{OH}) \mathrm{D}$ lev- 


\begin{tabular}{|c|c|c|c|}
\hline \multicolumn{4}{|c|}{$\begin{array}{l}\text { Table 1. The Clinical and Biochemical Features in Primary Hy } \\
\text { perparathyroidism }\end{array}$} \\
\hline Variable & $\begin{array}{c}\text { Primary } \\
\text { HPT } \\
(n=140)\end{array}$ & $\begin{array}{c}\text { Primary } \\
\text { HPT+PTC } \\
(n=14)\end{array}$ & $P$ value \\
\hline Age, yr & $54.8 \pm 11.8$ & $54.1 \pm 15.4$ & 0.10 \\
\hline \multicolumn{4}{|l|}{ Sex } \\
\hline Male & $34(24.3)$ & $3(21.4)$ & 1.00 \\
\hline Female & $106(75.7)$ & $11(78.6)$ & \\
\hline Body mass index, $\mathrm{kg} / \mathrm{m}^{2}$ & $24.0 \pm 3.8$ & $24.4 \pm 4.9$ & 0.12 \\
\hline PTH, pg/mL & $206.8 \pm 164.3$ & $207.4 \pm 138.7$ & 0.53 \\
\hline \multicolumn{4}{|l|}{ BMD, $\mathrm{g} / \mathrm{cm}^{2}$} \\
\hline Lumbar & $0.975 \pm 0.167$ & $0.931 \pm 0.275$ & 0.42 \\
\hline Total hip & $0.812 \pm 0.119$ & $0.838 \pm 0.206$ & 0.89 \\
\hline \multicolumn{4}{|l|}{ Parathyroid pathology } \\
\hline Adenoma & $117(83.6)$ & $14(100)$ & 0.70 \\
\hline Hyperplasia & $23(16.4)$ & 0 & \\
\hline Calcium, mg/dL & $10.8 \pm 1.0$ & $11.3 \pm 1.1$ & 0.87 \\
\hline Phosphorus, mg/dL & $2.7 \pm 0.5$ & $2.4 \pm 0.4$ & 0.19 \\
\hline $25(\mathrm{OH}) \mathrm{D}, \mathrm{ng} / \mathrm{mL}$ & $18.5 \pm 10.4$ & $13.0 \pm 3.7$ & 0.01 \\
\hline Blood urea nitrogen, mg/dL & $14.3 \pm 4.8$ & $15.2 \pm 3.1$ & 0.14 \\
\hline Creatinine, $\mathrm{mg} / \mathrm{dL}$ & $0.80 \pm 0.20$ & $0.75 \pm 0.20$ & 0.39 \\
\hline 24-hr urine calcium, mg/day & $345.7 \pm 141.9$ & $402.1 \pm 110.1$ & 0.14 \\
\hline \multicolumn{4}{|c|}{$\begin{array}{l}\text { Values are expressed as mean } \pm \text { standard deviation or number }(\%) \text {. Se- } \\
\text { rum calcium level is adjusted calcium for albumin. A two-tailed } P \text { value } \\
\text { of less than } 0.05 \text { was considered statistically significant. } \\
\text { HPT, hyperparathyroidism; PTC, papillary thyroid cancer; PTH, para- } \\
\text { thyroid hormone; BMD, bone mineral density; } 25(\mathrm{OH}) \mathrm{D}, 25 \text {-hy- } \\
\text { droxyvitamin D. }\end{array}$} \\
\hline
\end{tabular}

els were significantly higher in the pHPT-only group (18.5 \pm $10.4 \mathrm{ng} / \mathrm{mL})$ than in the $\mathrm{pHPT}+\mathrm{PTC}$ group $(13.0 \pm 3.7 \mathrm{ng} / \mathrm{mL})$ $(P=0.01)$ (Table 1).

\section{Clinical and biochemical characteristics of sHPT patients}

Table 2 shows the baseline characteristics of the SHPT patients. Concurrent PTC was detected in nine patients $(7.2 \%)$ with sHPT. There was no difference in sex and age between the subjects with SHPT and those with SHPT+PTC. The PTH level was $1,368.5 \pm 1,076.8 \mathrm{pg} / \mathrm{mL}$ in the sHPT-only group and $962.2 \pm$ $788.2 \mathrm{pg} / \mathrm{mL}$ in the sHPT+PTC group, with no significant difference between the two groups $(P=0.43)$. No specific biochemical variables were significantly different between the two groups. However, 25(OH)D levels were higher in the sHPT-only group $(18.0 \pm 10.2 \mathrm{ng} / \mathrm{mL})$ than in the $\mathrm{sHPT}+\mathrm{PTC}$ group $(12.3 \pm 5.6 \mathrm{ng} / \mathrm{mL})(P=0.12)$ (Table 2).
Table 2. The Clinical and Biochemical Features in Secondary Hyperparathyroidism

\begin{tabular}{lccc}
\hline Variable & $\begin{array}{c}\text { Secondary } \\
\text { HPT only } \\
(n=116)\end{array}$ & $\begin{array}{c}\text { Secondary } \\
\text { HPT }+ \text { PTC } \\
(n=9)\end{array}$ & $P$ value \\
\hline Age, yr & $49.4 \pm 11.4$ & $58.0 \pm 9.8$ & 0.43 \\
Sex & & & 0.30 \\
$\quad$ Male & $52(44.8)$ & $2(22.2)$ & \\
Female & $64(55.2)$ & $7(77.8)$ & \\
Body mass index, kg/m ${ }^{2}$ & $22.7 \pm 4.1$ & $21.1 \pm 2.2$ & 0.13 \\
PTH, pg/mL & $1,368.5 \pm 1,076.8$ & $962.2 \pm 788.2$ & 0.43 \\
BMD, g/cm ${ }^{2}$ & & & \\
Lumbar & $1.022 \pm 0.164$ & $0.957 \pm 0.093$ & 0.27 \\
Total hip & $0.798 \pm 0.164$ & $0.751 \pm 0.095$ & 0.32 \\
Parathyroid pathology & & & \\
Adenoma & $8(6.9)$ & $2(22.2)$ & 0.00 \\
Hyperplasia & $108(93.1)$ & $7(77.8)$ & \\
Calcium, mg/dL & $10.3 \pm 1.3$ & $10.1 \pm 1.2$ & 0.66 \\
Phosphorus, mg/dL & $4.8 \pm 2.0$ & $4.0 \pm 1.6$ & 0.31 \\
25(OH)D, ng/mL & $18.0 \pm 10.2$ & $12.3 \pm 5.6$ & 0.12 \\
Blood urea nitrogen, mg/dL & $44.3 \pm 23.8$ & $38.1 \pm 29.7$ & 0.33 \\
Creatinine, mg/dL & $6.6 \pm 4.6$ & $5.2 \pm 5.4$ & 0.38 \\
\hline
\end{tabular}

Values are expressed as mean \pm standard deviation or number (\%). Serum calcium level is adjusted calcium for albumin. A two-tailed $P$ value of less than 0.05 was considered statistically significant.

HPT, hyperparathyroidism; PTC, papillary thyroid cancer; PTH, parathyroid hormone; BMD, bone mineral density; 25(OH)D, 25-hydroxyvitamin D.

Clinical features of PTC in HPT and classical PTC patients The mean size of the PTC nodules in the HPT patients (concomitant PTC group) was $0.86 \pm 0.70 \mathrm{~cm}$. Among 23 cases, 17 (73.9\%) were microcarcinomas. All PTC nodules were either K-TIRADS 4 or K-TIRADS 5 in preoperative US examination. Extrathyroidal extension was found in $10(43.5 \%)$ cases. Lymph node metastasis was confirmed in $10(43.5 \%)$ cases, and the LNR was $21.8 \% \pm 33.2 \%$ in the concomitant PTC group.

The mean size of the PTC nodules in the classical PTC group was $0.90 \pm 0.60 \mathrm{~cm} ; 71$ nodules $(72.4 \%)$ were microcarcinomas. Extrathyroidal invasion was found in 34 (34.7\%) cases. Lymph node metastasis was confirmed in $32(32.6 \%)$ cases, and the LNR was $10.3 \% \pm 20.3 \%$ in patients with classical PTC. Extrathyroidal extension and lymph node metastasis were more common in the concomitant PTC group than in the classical PTC group, but the difference was not statistically significant $(P=$ 0.47 and $P=0.34$, respectively). The LNR was significantly 
Table 3. Clinical Differences between Concomitant Papillary Thyroid Cancer and Classical Papillary Thyroid Cancer

\begin{tabular}{|c|c|c|c|}
\hline Variable & $\begin{array}{c}\text { Concomitant } \\
\text { PTC } \\
(n=23)\end{array}$ & $\begin{array}{c}\text { Classical } \\
\text { PTC } \\
(n=98)\end{array}$ & $P$ value \\
\hline Age, yr & $55.0 \pm 13.5$ & $52.0 \pm 11.6$ & 0.54 \\
\hline \multicolumn{4}{|l|}{ Sex } \\
\hline Male & $5(21.8)$ & $22(22.4)$ & \multirow[t]{2}{*}{1.00} \\
\hline Female & $18(78.2)$ & $76(77.6)$ & \\
\hline Tumor size, cm & $0.86 \pm 0.70$ & $0.90 \pm 0.60$ & 0.92 \\
\hline Microcarcinoma & $17(73.9)$ & $71(72.4)$ & 1.00 \\
\hline \multicolumn{4}{|l|}{ Echogenicity } \\
\hline Hypoechoic & $20(87.0)$ & 77 (78.6) & \multirow[t]{3}{*}{0.56} \\
\hline Isoechoic & $3(13.0)$ & $21(21.4)$ & \\
\hline Hyperechoic & 0 & 0 & \\
\hline \multicolumn{4}{|l|}{ Margin } \\
\hline Ill-defined & $6(26.1)$ & $33(33.7)$ & \multirow[t]{2}{*}{0.62} \\
\hline Well-defined & $17(73.9)$ & $65(66.3)$ & \\
\hline \multicolumn{4}{|l|}{ Shape } \\
\hline Parallel & $13(56.5)$ & $55(56.1)$ & \multirow[t]{2}{*}{1.00} \\
\hline Non-parallel & $10(43.5)$ & $43(43.2)$ & \\
\hline \multicolumn{4}{|l|}{ K-TIRADS } \\
\hline 4 & $6(26.1)$ & $37(37.8)$ & \multirow[t]{2}{*}{0.34} \\
\hline 5 & $17(73.9)$ & $61(62.2)$ & \\
\hline Extrathyroidal extension & $10(43.5)$ & $34(34.7)$ & 0.47 \\
\hline Lymph node metastasis & $10(43.5)$ & $32(32.6)$ & 0.34 \\
\hline $\mathrm{LNR}, \%$ & $21.8 \pm 33.2$ & $10.3 \pm 20.3$ & 0.00 \\
\hline \multicolumn{4}{|l|}{ BRAF mutation } \\
\hline Yes & $13(56.5)$ & $86(87.8)$ & \multirow[t]{3}{*}{0.00} \\
\hline No & $2(8.7)$ & $11(11.2)$ & \\
\hline Unknown & $8(34.8)$ & $1(1.0)$ & \\
\hline
\end{tabular}

Values are expressed as mean \pm standard deviation or number (\%). Concomitant PTC includes PTC in primary hyperparathyroidism and secondary hyperparathyroidism. A two-tailed $P$ value of less than 0.05 was considered statistically significant.

PTC, papillary thyroid cancer; K-TIRADS, Korean Thyroid Imaging Reporting and Data System; LNR, lymph node ratio; BRAF, B-type Raf kinase.

higher in the concomitant PTC group than in the classical PTC group $(P=0.00)$ (Table 3$)$.

\section{DISCUSSION}

In our research, $9.1 \%$ of the pPHT cases and $7.2 \%$ of the sPHT cases requiring parathyroidectomy had concomitant PTC. The serum 25(OH)D levels were lower in the group with concomitant PTC+HPT than in the group with HPT only. The coexisting cases of PTC were mostly microcarcinomas and had more aggressive features.

In previous literature, the prevalence of concomitant PTC in pPHT ranged from $2 \%$ to $15 \%$, consistent with our results. Preda et al. [18] recently reported the incidence of thyroid cancer in patients with sHPT to be $11.7 \%$, which was higher than our findings of $7.2 \%$. Our study demonstrated that the incidence of PTC was high and similar in both patients with pHPT and sHPT.

The mechanism of the relationship between HPT and concomitant PTC is still unclear. Pickard et al. [19] reported that thyroid malignancy was the most prevalent cancer among patients whose primary disorder was pHPT. Several possible explanations have been proposed as the mechanism for the association. First, high PTH levels have been reported to af $\neg$ fect phagocytosis, T-cell sensitivity, and B-cell function, thus contributing to the immune dysfunction of patients and in $\neg$ creasing the incidence of cancer [20]. Some authors postulated that PTH could increase the hepatic synthesis of insulin-like growth factor 1 [21], leading to thyroid cell growth [22]. Likewise, a study suggested that high levels of PTH might predict the existence of PTC in pHPT patients [23]. Second, long-term exposure to elevated calcium has also been reported to be carcinogenic. The goitrogenic effect of calcium is due to the inhibition of thyroxine synthesis. Hypercalcemia and the excessive production of calcitonin in response to hypercalcemia have been proposed as a common pathogenic mechanism [24]. Third, low levels of vitamin D were associated with concomitant PTC in patients with HPT in our study. A previous study also reported low vitamin D concentrations in patients with severe pHPT [23]. It is well known that vitamin $\mathrm{D}$ is associated with anti-proliferative, prodifferentiative, pro-apoptotic, and anti-inflammatory actions within the tumor microenvironment [25]. Several clinical studies have suggested low vitamin D levels as a risk factor for thyroid cancer associated with incidence and worse outcome $[26,27]$. The level of vitamin D can vary according to outdoor activity, diet, and the time of measurement. However, considering that the mean vitamin D level in Korea was reported to be $18.5 \pm 8.1 \mathrm{ng} / \mathrm{mL}$ [28], our study showing significantly lower levels of vitamin D in HPT patients with concomitant PTC has some implications. Further research is needed to clarify the association of vitamin D with HPT in patients with concomitant PTC.

Lymph node metastasis and extrathyroidal invasion are asso- 
ciated with aggressive features in PTC [16,29-31]. Of the concomitant PTC cases, $43.5 \%$ had lymph node metastasis and presented with extrathyroidal invasion, suggesting high-risk features [16,29-31]. A previous study reported that the optimal LNR threshold value for predicting PTC recurrence was $17.86 \%$ [32]. Our study showing high LNRs in concomitant PTC $(21.8 \% \pm 33.2 \%)$ compared to the control group (10.3\%土 $20.3 \%$ ), might represent a high risk of recurrence in these groups. Therefore, our study suggests that PTC in HPT patients represents a higher risk feature than PTC incidentally found in the general population.

A high rate of microcarcinoma has been reported in patients with concomitant HPT [33], consistent with our research showing 16 cases (73.9\%) of microcarcinoma (10 in pHPT and seven in SHPT) in 23 thyroid papillary cancers. Subcentimeter microcarcinoma is associated with a low disease-specific mortality, and certain authors and guidelines have recommended active surveillance instead of surgery as a reasonable option for papillary microcarcinoma [34]. However, considering the highly aggressive feature of concomitant PTC in our study, we suggest that active surveillance should be considered carefully, even in cases of microcarcinoma. Further study is needed to clarify the implication of concomitant PTC.

The routine FNA of K-TIRADS five nodules lesser than $1 \mathrm{~cm}$ in size is not recommended by the Korean Thyroid Association guidelines unless suspicious malignant features are present. Moreover, the guidelines do not recommend FNA of subcentimeter K-TIRADS four nodules since they have a low risk of malignancy [17]. However, in our study, several subcentimeter K-TIRADS four nodules were proven malignant and presented aggressive features. Thus, efforts should be made to detect the coexistent PTC in HPT patients for any subcentimeter nodule prior to parathyroidectomy. Considering the aggressiveness of concomitant PTC, overlooking subcentimeter concomitant thyroid nodules in HPT patients may mean missing PTC with highrisk features that can lead to multiple surgeries and several complications [35]. Vaiman et al. [36] reported that injury to the recurrent laryngeal nerve occurred in $1.4 \%$ of the primary thyroidectomy compared to $3 \%$ of the patients undergoing reoperation thyroidectomy. To avoid reoperation, preoperative US evaluation is necessary before parathyroidectomy. By searching for concomitant thyroid nodules with preoperative US, indeterminate lesions that require additional evaluation can be detected.

There are several limitations in our study. First, since this study is retrospective, we were unable to clarify the causal relationships and underlying mechanisms in the research. Second, we were unable to investigate several factors that could have affected serum calcium and vitamin D levels, such as taking health supplements or other medication, a lack of sun exposure, and exercising. Lastly, the small sample size without a control group is a limitation. A study with a larger population may allow more significant conclusions about PTC in HPT patients to be drawn.

In conclusion, to our knowledge, this is the first study evaluating the incidence of concomitant PTC in patients with HPT in Korea. A high prevalence of concomitant PTC in pHPT and sHPT patients was shown and concomitant PTC had more aggressive features than incidentally detected PTC. As a minimally invasive approach for parathyroidectomy has replaced bilateral neck exploration, thorough preoperative thyroid evaluation is necessary to identify concomitant PTC.

\section{CONFLICTS OF INTEREST}

No potential conflict of interest relevant to this article was reported.

\section{AUTHOR CONTRIBUTIONS}

Conception or design: H.S.K., D.J.L., K.H.B., J.H., M.I.K. Acquisition, analysis, or interpretation of data: C.J., H.I.K., H.B. Drafting the work or revising: C.J., J.H. Final approval of the manuscript: M.I.K.

\section{ORCID}

Chaiho Jeong https://orcid.org/0000-0002-2914-2278

Jeonghoon Ha https://orcid.org/0000-0001-9219-7135

\section{REFERENCES}

1. Heath DA. Primary hyperparathyroidism. Clinical presentation and factor influencing clinical management. Endocrinol Metab Clin North Am 1989;18:631-46.

2. Darba J, Marsa A. Epidemiology and management of parathyroid gland disorders in Spain over 15 years: a retrospective multicentre analysis. PLoS One 2020;15:e0230130.

3. Collier A, Portelli M, Ghosh S, Nowell S, Clark D. Primary hyperparathyroidism: increasing prevalence, social deprivation, and surgery. Endocr Res 2017;42:31-5.

4. Fraser WD. Hyperparathyroidism. Lancet 2009;374:145-58.

5. Pitt SC, Sippel RS, Chen H. Secondary and tertiary hyper- 
parathyroidism, state of the art surgical management. Surg Clin North Am 2009;89:1227-39.

6. Kim SM, Long J, Montez-Rath ME, Leonard MB, Norton JA, Chertow GM. Rates and outcomes of parathyroidectomy for secondary hyperparathyroidism in the United States. Clin J Am Soc Nephrol 2016;11:1260-7.

7. Ogburn PL, Black BM. Primary hyperparathyroidism and papillary adenocarcinoma of the thyroid: report of four cases. Proc Staff Meet Mayo Clin 1956;31:295-8.

8. Yazici P, Mihmanli M, Bozdag E, Aygun N, Uludag M. Incidental finding of papillary thyroid carcinoma in the patients with primary hyperparathyroidism. Eurasian J Med 2015;47: 194-8.

9. Cinamon U, Levy D, Marom T. Is primary hyperparathyroidism a risk factor for papillary thyroid cancer? An exemplar study and literature review. Int Arch Otorhinolaryngol 2015;19:42-5.

10. Burmeister LA, Sandberg M, Carty SE, Watson CG. Thyroid carcinoma found at parathyroidectomy: association with primary, secondary, and tertiary hyperparathyroidism. Cancer 1997;79:1611-6.

11. Smit PC, Borel Rinkes IH, van Dalen A, van Vroonhoven TJ. Direct, minimally invasive adenomectomy for primary hyperparathyroidism: an alternative to conventional neck exploration? Ann Surg 2000;231:559-65.

12. Wright MC, Jensen K, Mohamed H, Drake C, Mohsin K, Monlezun D, et al. Concomitant thyroid disease and primary hyperparathyroidism in patients undergoing parathyroidectomy or thyroidectomy. Gland Surg 2017;6:368-74.

13. Bilezikian JP, Brandi ML, Eastell R, Silverberg SJ, Udelsman R, Marcocci C, et al. Guidelines for the management of asymptomatic primary hyperparathyroidism: summary statement from the Fourth International Workshop. J Clin Endocrinol Metab 2014;99:3561-9.

14. Lau WL, Obi Y, Kalantar-Zadeh K. Parathyroidectomy in the management of secondary hyperparathyroidism. Clin J Am Soc Nephrol 2018;13:952-61.

15. Shin JH, Baek JH, Chung J, Ha EJ, Kim JH, Lee YH, et al. Ultrasonography diagnosis and imaging-based management of thyroid nodules: revised Korean Society of Thyroid Radiology consensus statement and recommendations. Korean J Radiol 2016;17:370-95.

16. Ha J, Lee J, Jo K, Han JS, Kim MH, Jung CK, et al. Calcification patterns in papillary thyroid carcinoma are associated with changes in thyroid hormones and coronary artery calcification. J Clin Med 2018;7:183.
17. Yi KH, Lee EK, Kang HC, Koh Y, Kim SW, Kim IJ, et al. 2016 Revised Korean Thyroid Association management guidelines for patients with thyroid nodules and thyroid cancer. Int J Thyroidol 2016;9:59-126.

18. Preda C, Branisteanu D, Armasu I, Danila R, Velicescu C, Ciobanu D, et al. Coexistent papillary thyroid carcinoma diagnosed in surgically treated patients for primary versus secondary hyperparathyroidism: same incidence, different characteristics. BMC Surg 2019;19:94.

19. Pickard AL, Gridley G, Mellemkjae L, Johansen C, KofoedEnevoldsen A, Cantor KP, et al. Hyperparathyroidism and subsequent cancer risk in Denmark. Cancer 2002;95:1611-7.

20. Geara AS, Castellanos MR, Bassil C, Schuller-Levis G, Park E, Smith M, et al. Effects of parathyroid hormone on immune function. Clin Dev Immunol 2010;2010:418695.

21. McCarty MF. Parathyroid hormone may be a cancer promoter: an explanation for the decrease in cancer risk associated with ultraviolet light, calcium, and vitamin D. Med Hypotheses 2000;54:475-82.

22. Maiorano E, Ambrosi A, Giorgino R, Fersini M, Pollice L, Ciampolillo A. Insulin-like growth factor 1 (IGF-1) in multinodular goiters: a possible pathogenetic factor. Pathol Res Pract 1994;190:1012-6.

23. Vargas-Ortega G, Balcazar-Hernandez L, Gonzalez-Virla B, Ramirez-Renteria C, Nieto-Guzman O, Garrido-Mendoza AP, et al. Symptomatic primary hyperparathyroidism as a risk factor for differentiated thyroid cancer. J Thyroid Res 2018;2018:9461079.

24. Beebeejaun M, Chinnasamy E, Wilson P, Sharma A, Beharry N, Bano G. Papillary carcinoma of the thyroid in patients with primary hyperparathyroidism: is there a link? Med Hypotheses 2017;103:100-4.

25. Kim D. The role of vitamin D in thyroid diseases. Int J Mol Sci 2017;18:1949.

26. Roskies M, Dolev Y, Caglar D, Hier MP, Mlynarek A, Majdan A, et al. Vitamin D deficiency as a potentially modifiable risk factor for thyroid cancer. J Otolaryngol Head Neck Surg 2012;41:160-3.

27. Kim JR, Kim BH, Kim SM, Oh MY, Kim WJ, Jeon YK, et al. Low serum 25 hydroxyvitamin D is associated with poor clinicopathologic characteristics in female patients with papillary thyroid cancer. Thyroid 2014;24:1618-24.

28. Wee JH, Cho SW, Kim JW, Rhee CS. Serum vitamin D levels in a healthy Korean population. J Allergy Clin Immunol 2018;141(2 Suppl):AB77.

29. Jeon MJ, Chung MS, Kwon H, Kim M, Park S, Baek JH, et 
al. Features of papillary thyroid microcarcinoma associated with lateral cervical lymph node metastasis. Clin Endocrinol (Oxf) 2017;86:845-51.

30. Jeon MJ, Kim WG, Choi YM, Kwon H, Lee YM, Sung TY, et al. Features predictive of distant metastasis in papillary thyroid microcarcinomas. Thyroid 2016;26:161-8.

31. Kim SK, Park I, Woo JW, Lee JH, Choe JH, Kim JH, et al. Predictive factors for lymph node metastasis in papillary thyroid microcarcinoma. Ann Surg Oncol 2016;23:2866-73.

32. Lee J, Lee SG, Kim K, Yim SH, Ryu H, Lee CR, et al. Clinical value of lymph node ratio integration with the 8th edition of the UICC TNM classification and 2015 ATA risk stratification systems for recurrence prediction in papillary thyroid cancer. Sci Rep 2019;9:13361.
33. Cetin K, Sikar HE, Temizkan S, Ofluoglu CB, Ozderya A, Aydin K, et al. Does primary hyperparathyroidism have an association with thyroid papillary cancer? A retrospective cohort study. World J Surg 2019;43:1243-8.

34. Haser GC, Tuttle RM, Su HK, Alon EE, Bergman D, Bernet $\mathrm{V}$, et al. Active surveillance for papillary thyroid microcarcinoma: new challenges and opportunities for the health care system. Endocr Pract 2016;22:602-11.

35. Wilhelm SM, Wang TS, Ruan DT, Lee JA, Asa SL, Duh QY, et al. The American Association of Endocrine Surgeons guidelines for definitive management of primary hyperparathyroidism. JAMA Surg 2016;151:959-68.

36. Vaiman M, Nagibin A, Olevson J. Complications in primary and completed thyroidectomy. Surg Today 2010;40:114-8. 